\title{
Anger and Self-Esteem amongst Alcohol Addicts and Drug Addicts
}

\author{
Nikita D'Souza ${ }^{1}$ \\ ${ }^{1}$ Consultant Psychologist, Indla Child Guidance Centre, Mumbai \\ E-mail-nikki.nd27@gmail.com
}

\begin{abstract}
Introduction: The purpose of this study was to examine the difference in the levels of anger and selfesteem among alcohol addicts and drug addicts. A sample of 60 male substance abusers, out of which 30 were alcohol addicts and the other 30 were drug addicts was taken. They were given two questionnaires i.e. the Clinical Anger Scale (CAS) and Rosenberg's Self-Esteem Scale (RSES) and scores on both the scales were thus obtained. It was found that there was no significant difference in the levels of anger among alcohol addicts and drug addicts. It was also found that there was no significant difference in the self-esteem of alcohol addicts and drug addicts.

Methodology: The researcher made use of Random Sampling during the present study, which comprised of 30 Alcohol Addicts and 30 Drug Addicts. This sample was selected from rehabilitation centers, Alcohol Anonymous Groups, and hospitals. The sample of Alcohol Addicts and Drug Addicts were taken to be in the age range of 16 to 65 years. The following hypotheses were tested in the study- There is a significant difference in the levels of anger between Alcohol Addicts and Drug Addicts; and there is a significant difference in the levels of self-esteem between Alcohol Addicts and Drug Addicts.

Results: The result of the t-test draws to a conclusion that the obtained value is lesser than the table value. The Mean for Alcohol Addicts was 22.23 while that for Drug Addicts was 27.36. There is a difference between the Means of the two groups the data is in the expected direction. A t-test was conducted to carry out further statistical analysis to find out if there was a significant difference between the two means of the groups. The obtained $t$ value was 1.49 .

Conclusion: The first hypothesis stated that there is a significant difference in the levels of anger between Alcohol Addicts and Drug Addicts and the second hypothesis stated that there is a significant difference in the levels of self-esteem between Alcohol Addicts and Drug Addicts- data was not found to be supportive of both these hypotheses. The findings suggest that both the alternate hypotheses were rejected as the obtained t-value was less than the table value at 0.05 level of significance, with df 58 . Thus, the level of anger and level of self esteem are subjective to various reasons among Alcohol and Drug Addicts.
\end{abstract}

Key Words: Alcohol Addict, Drug Addict, Aggression, Self Esteem, Clinical Anger Scale (CAS), Rosenberg's Self-Esteem Scale (RSES).

(Paper received $-12^{\text {th }}$ February 2016, Peer review completed $-4^{\text {th }}$ April 2016, Accepted $-6^{\text {th }}$ May 2016)

\section{INTRODUCTION}

According to the American Psychological Association, Anger is an emotion characterized by antagonism toward someone or something one feels has deliberately done one wrong. Anger can be a good thing. It can give one a way to express negative feelings, for example, or motivate one to find solutions to problems. But excessive anger can cause problems. Increased blood pressure and other physical changes associated with anger make it difficult to think straight and harm your physical and mental health [1-2]. Three types of anger are recognized by psychologists: The first form of anger, named "hasty and sudden anger", the second type of anger is named "settled and deliberate" anger and the third type of anger is called 
dispositional anger [3]. One simple dichotomy of anger expression is Passive anger versus Aggressive anger [4]. According to the Cognitive Behavior Theory, anger is a consequence of many causes such as cognitive, social/or behavioral models that we have learned from others, the lack of social skills and problem solving strategies, and several biological factors. The main cause of anger is represented by our irrational perceptions and evaluations of situations when our rights and goals are apparently broken. Put in simpler terms, thoughts are the underlying factor of anger [5]. There are many therapists, classes, and programs for people with anger management problems. Asking for help is not a sign of weakness. One will often find others in the same shoes, and getting direct feedback on techniques for controlling anger can be tremendously helpful.

\section{Myths and Facts about Anger}

Myth: I shouldn't "hold in" my anger. It's healthy to vent and let it out.

Fact: While it's true that suppressing and ignoring anger is unhealthy, venting is no better. Anger is not something you have to "let out" in an aggressive way in order to avoid blowing up. In fact, outbursts and tirades only fuel the fire and reinforce your anger problem.

Myth: Anger, aggression, and intimidation help me earn respect and get what I want.

Fact: True power doesn't come from bullying others. People may be afraid of you, but they won't respect you if you can't control yourself or handle opposing viewpoints. Others will be more willing to listen to you and accommodate your needs if you communicate in a respectful way.

Myth: I can't help myself. Anger isn't something you can control.

Fact: You can't always control the situation you're in or how it makes you feel, but you can control how you express your anger. And you can express your anger without being verbally or physically abusive. Even if someone is pushing your buttons, you always have a choice about how to respond.

Myth: Anger management is about learning to suppress your anger.

Fact: Never getting angry is not a good goal. Anger is normal, and it will come out regardless of how hard you try to suppress it. Anger management is all about becoming aware of your underlying feelings and needs and developing healthier ways to manage upset. Rather than trying to suppress your anger, the goal is to express it in constructive ways.

According to the American Psychological Association, self-esteem is a generalized evaluative attitude toward the self that influences both moods and behavior and that exerts a powerful effect on a range of personal and social behaviours [6]. Self-esteem is used to describe a person's overall sense of self-worth or personal value. Self-esteem is often seen as a personality trait, which means that it tends to be stable and enduring. Self-esteem can involve a variety of beliefs about the self, such as the appraisal of one's own appearance, beliefs, emotions and behaviours [7]. The need for self-esteem plays an important role in psychologist Abraham Maslow's hierarchy of needs, depicting self-esteem as one of the basic human motivations. The synonyms of self-esteem include Self-worth, Self-respect and Self-value [8]. According to one definition, there are three key components of self-esteem - Self-esteem is an essential human need that is vital for survival and normal, healthy development, Self-esteem arises automatically from within based upon a person's beliefs and consciousness and Self-esteem occurs in conjunction with a person's thoughts, behaviors, feelings and actions [9].

According to the American Psychological Association, Addiction is a condition in which the body requires a drug in order to function without physical and psychological reactions to its absence; often the outcome of tolerance and dependence [10]. Alcoholism is a broad term for problems with alcohol, and is generally used to mean compulsive and uncontrolled consumption of alcoholic beverages, usually to the detriment of the drinker's health, personal relationships, and social standing. It is medically considered a disease, specifically an addictive illness [11]. Long-term alcohol abuse can cause a number of physical symptoms, including cirrhosis of the liver, pancreatitis, epilepsy, polyneuropathy, alcoholic dementia, heart disease, nutritional deficiencies, peptic ulcers and sexual dysfunction, and can eventually be fatal [12]. 


\section{METHODOLOGY}

Hypothesis 1 - There is a significant difference in the levels of anger between Alcohol Addicts and Drug Addicts.

Hypothesis 2 - There is a significant difference in the levels of self-esteem between Alcohol Addicts and Drug Addicts

The researcher made use of Random Sampling during the present study, which comprised of 30 Alcohol Addicts and 30 Drug Addicts. This sample was selected from rehabilitation centers, Alcohol Anonymous Groups, and hospitals.

The sample of Alcohol Addicts and Drug Addicts were taken to be in the age range of 16 to 65 years.

The following tools were utilized for the data collection -

The Clinical Anger Scale (CAS): An objective self-report instrument--the Clinical Anger Scale (CAS)-was designed to measure the psychological symptoms presumed to have relevance in the understanding and treatment of clinical anger. Twenty-one sets of statements were prepared for this purpose. In writing these groups of items, the format from one of Beck's early instruments was used to design the Clinical Anger Scale [13]. The following symptoms of anger were measured by the CAS items: anger now, anger about the future, anger about failure, anger about things, angry-hostile feelings, annoying others, angry about self, angry misery, wanting to hurt others, shouting at people, irritated now, social interference, decision interference, alienating others, work interference, sleep interference, fatigue, appetite interference, health interference, thinking interference, and sexual interference.

The Rosenberg self-esteem scale (RSES):_The Rosenberg Self-Esteem Scale (RSES), developed by sociologist Dr. Morris Rosenberg, in the year 1965, is a self-esteem measure widely used in social-science research. The RSES is designed similar to social-survey questionnaires. It is a ten item Likert-type scale with items answered on a four-point scale - from strongly agree to strongly disagree. Five of the items have positively worded statements and five have negatively worded ones. The scale measures state self-esteem by asking the respondents to reflect on their current feelings. The original sample for which the scale was developed consisted of 5,024 high-school juniors and seniors from 10 randomly selected schools in New York State. The Rosenberg self-esteem scale is considered a reliable and valid quantitative tool for self-esteem assessment [14].

The Research Design employed during the current research was a Random Groups Design, with one Independent Variable i.e. Substance Abusers, having two levels, i.e. Alcohol Addicts and Drug Addicts.

The data for the present study was collected randomly from participants across hospitals, rehabilitation centres and Alcoholics Anonymous Groups. The various centres were individually contacted to gain permission for data collection, providing all the necessary details and documents required.

After permission was granted, data was collected by administering the two questionnaires to each individual participant in the case of the hospital and Alcoholics Anonymous Group. As in the case of the rehabilitation centre, the questionnaires were administered to the all participants available, in a group. Before the participants began answering the questionnaires, they were briefed about the researcher and the nature and purpose of the study. They were asked to fill in their demographic details on the first page and then read the consent form that followed. For participants who could not read English, the details of the consent form was read out in Hindi, after ensuring that they followed the language.

The participants were then given the instructions before they could begin filling in the questionnaires, in the simplest words possible.

\section{RESULTS}

There were 30 participants in each group. The alcohol addicts group included only patients with Alcohol Dependence and the Drug addict group included patients with other addictions excluding alcohol. Patients with Nicotine dependence were included in each group. 
The Mean for Alcohol Addicts was 22.23 while that for Drug Addicts was 27.36. Thus, by looking at the Means of the two groups, a comparison can be made. Since there is a difference between the Means of the two groups, the data is in the expected direction. A t-test was conducted to carry out further statistical analysis to find out if there was a significant difference between the two means of the groups. The obtained $t$ value was 1.49 while the table value was 2.000 at a 0.05 level of significance.

The result of the t-test draws to a conclusion that the obtained value is lesser than the table value. Hence, there is no significant difference in the level of anger experienced, between the two groups.

Table 1 - Mean scores across both the groups

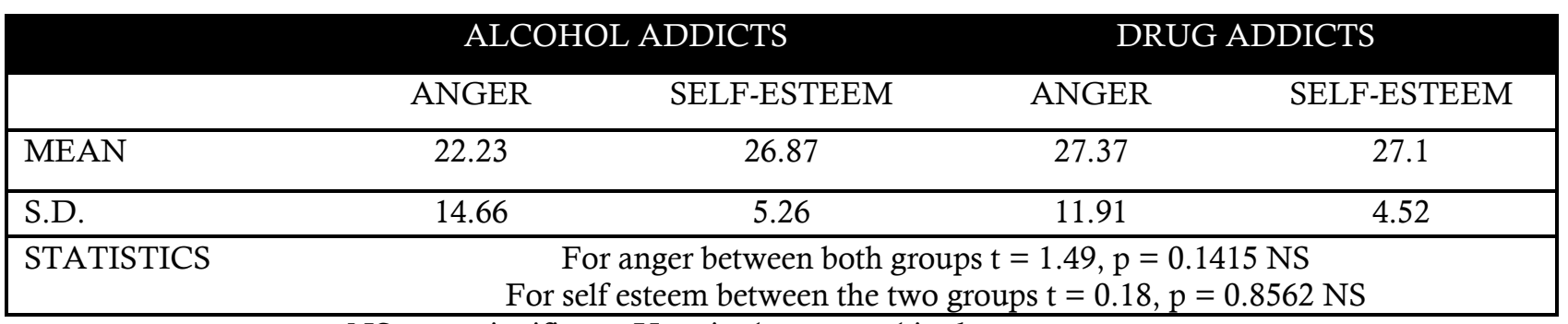

NS - not significant, Unpaired t test used in the assessment

\section{DISCUSSION}

In our study there was no difference on any parameter between the two groups. Social influence processes play an important role in the development of alcohol dependence [15]. Research suggests that individuals with insecure attachment style tend to seek use of alcohol or illicit drugs, as a coping mechanism for emotional self-regulation [16]. This is very often manifested as anger, aggression and low self esteem. Anger as trait or 'trait anger' is classified under anger experience along with state anger. Anger expression, which is further sub-divided into anger in and anger out and anger control are the other two broad categories of anger along with anger experience [17]. Studies indicate that problematic alcohol use is related consistently to significantly higher anger expression and significantly lower anger control [18].

It is suggested that both low and high self-esteem might lead to aggression. Self-esteem, which is defined operationally as an evaluation of the self and includes how the person feels about him or her or a personal judgment of worthiness may vary in patients with alcoholism [19]. Mixed results confound literature on the relationship between alcohol dependence and self esteem [20]. Limited sample size and only male subjects limit the findings of our study. It is suggested that future work should include larger sample sizes across diverse settings and subjects of both genders and different forms of substance abuse.

\section{REFERENCES}

1. Howells K, Day A. Readiness for anger management: Clinical and theoretical issues. Clin Psychol Rev 2003;23(2):319-37.

2. Ahmed AG, Kingston DA, DiGiuseppe R, Bradford JM, Seto MC. Developing a clinical typology of dysfunctional anger. J Affect Disord 2012;136(1):139-48.

3. Kopper BA, Epperson DL. Sex and sex-role comparisons in the expression of anger. Psychol Women Quart 1991;15(1):7-14.

4. Beck R, Fernandez E. Cognitive-behavioral therapy in the treatment of anger: A meta-analysis. Cogn Ther Res 1998;22(1):63-74.

5. Deffenbacher JL. Cognitive-behavioral conceptualization and treatment of anger. J Clin Psychol 1999;55(3):295-309.

6. Branden N. The psychology of self-esteem: A new concept of man's psychological nature. Bantam Books; 1971.

7. Mruk CJ. Self-esteem research, theory, and practice: Toward a positive psychology of self-esteem. Springer Publishing Company; 2006. 
8. Branden N. The psychology of self-esteem: a revolutionary approach to self-understanding that launched a new era in modern psychology. Jossey-Bass; 2001.

9. Beane JA, Lipka RP. Self concept, self esteem and curriculum. New York : Teachers College Press ; 1986.

10. Wanigaratne S. Psychology of addiction. Psychiatry 2006;5(12):455-60.

11. Levin JD. Treatment of alcoholism and other addictions: A self-psychology approach. Jason Aronson; 1987.

12. Leonard KE, Blane HT. Psychological theories of drinking and alcoholism. Guilford Press; 1999.

13. Snell WE, Gum S, Shuck RL, Mosley JA, Kite TL. The clinical anger scale: preliminary reliability and validity. J Clin Psychol 1995;51(2):215-26.

14. Robins RW, Hendin HM, Trzesniewski KH. Measuring global self-esteem: Construct validation of a singleitem measure and the Rosenberg Self-Esteem Scale. Personal Soc Psychol Bull 2001;27(2):151-61.

15. Wood MD, Read JP, Palfai TP, Stevenson JF. Social influence processes and college student drinking: The mediational role of alcohol outcome expectancies. J Stud Alcohol. 2001;62:32-43.

16. DeMojá CA, Spielberger CD. Anger and drug addiction. Psychol Rep 1997;81:152-4.

17. Tivis LJ, Parsons OA, Nixon SJ. Anger in an inpatient treatment sample of chronic alcoholics. Alcohol Clin Exp Res 1998;22:902-7.

18. Bushman BJ, Cooper HM. Effects of alcohol on human aggression: An integrative research review. Psychol Bull 1990;107:341-54.

19. Lewisa MA, Phillippi J, Neighbors C. Morally Based Self-Esteem, drinking motives, and alcohol use among college students. Psychol Addict Behav 2007;21:398-403.

20. Tikka DL, Ram D, Dubey I, Tikka SK. Socio-emotional factors in alcohol dependence. Indian J Psychol Med 2014;36(2):154-7.

\author{
Acknowledgements - Nil \\ Source of Funding - Nil \\ Conflict of Interest - Nil
}

